\title{
Assessing the Use of a Surface Washing Agent for Treating Oil Spills in Canada's Freshwater Environments
} \author{
Shanoff ${ }^{4}$ and Elliott Taylor ${ }^{5}$ \\ ${ }^{1}$ International Institute for Sustainable Development- Experimental Lakes Area, Canada \\ ${ }^{2}$ University of Manitoba, Winnipeg, Canada \\ ${ }^{3}$ University of Guelph, School of Environmental Sciences, Canada \\ ${ }^{4}$ Stantec Consultants Ltd, Canada
}

Vince P Palace ${ }^{1,2 *}$, Gregg Tomy ${ }^{2}$, Lisa Peters ${ }^{2}$, Jose Luis Rodriguez Gil ${ }^{1,2}$, Tyler A Black ${ }^{3}$, Lauren Timlick ${ }^{1}$, Tanya

${ }^{5}$ Polaris Applied Sciences, Bainbridge Island, USA

Submission: October 14, 2021; Published: October 28, 2021

*Corresponding author: Vince P Palace, International Institute for Sustainable Development- Experimental Lakes Area Winnipeg, Manitoba, Canada

\begin{abstract}
The use of spill treating agents for remediating oil spills is intended to achieve net environmental benefit for chemical and biological recovery. Spill treating agents, including dispersants and surface washing agent (SWA), are generally used only in marine systems. Dispersants require sufficient mixing energy and dilution, but surface washing agents facilitate lifting of oil from surfaces. Surface washing agents are specifically intended to mobilize stranded oil from substrates, allowing the freed product to be collected using sorbent media or skimming once it is washed from the shore into the adjacent aquatic environment. In response to evidence that SWA may also be useful in low energy freshwater environments, we field tested the efficacy of Corexit EC9580 $\mathrm{A}^{\mathrm{TM}}$ for removing weathered heavy oil from two physically different shoreline types in a freshwater boreal lake in Northwestern Ontario, Canada. The SWA removed more oil from rock/cobble shorelines (56 $\pm 14 \%)$ compared to organic wetland shorelines $(13 \pm 3 \%)$. Marginal efficacy coupled with concern for negative impacts to benthic and surface-dwelling freshwater biota, suggest that Corexit EC9580A $\mathrm{A}^{\mathrm{TM}}$ may provide some benefit for rocky/cobble shorelines but should not be considered as part of primary oil spill response measures in low energy freshwater environments with organic sediments.
\end{abstract}

Keywords: Spill treating agents; Biological recovery; Organic sediments; Freshwater environments; Corexit EC9580A ${ }^{\text {TM }}$

\section{Introduction \& Review}

In May 2016 Canada's Minister of the Environment promulgated new regulations under the Canada Oil and Gas Operations Act authorizing the use of oil spill treated agents for marine environments [1]. These Regulations pertained to two separate products; a dispersant (Corexit EC9500A $\mathrm{A}^{\mathrm{TM}}$ ) and another product that can be used either as a herding agent or a surface washing agent (SWA) (Corexit EC9580A $\mathrm{A}^{\mathrm{TM}}$ ). These spill treating products were identified based on their efficacy, low toxicity, and their ability to confer a net environmental benefit for oil spill scenarios [1]. The Regulations permitted the use of these products only in marine environments, presumably because freshwater environments lack sufficient wave energy and water circulation to achieve effective dispersion of oil and post-treatment dilution of the
SWA, respectively [2]. However, previous work has suggested that spill treating agents may be effective in some low energy environments, including wetlands where stranding of oil is a concern or where sensitive vegetation or biota are present $[3,4]$. Part of the evaluation for registering these products included toxicity testing using organisms that are also endemic to freshwater environments (e.g., rainbow trout, three spined stickleback and Daphnia $s p$.). The assessment of safety based on the supporting tests suggested that the spill treating agents might also be safe for freshwater applications [5,6], but because these products are not currently registered for use in freshwaters, opportunities to test their efficacy in real world spill scenarios are lacking. 
The IISD-Experimental Lakes Area (IISD-ELA) is a field research station consisting of 58 boreal lakes set aside for research in Northwestern Ontario, Canada. The field station has operated continuously since 1968 and researchers are afforded the ability to manipulate lakes by virtue of specific legislation that applies to the facility at the provincial (Ontario Regulation 60/14: Experimental Lakes Area) and federal levels (Fisheries Act, Section 36(5.2) Experimental Lakes Area Research Activities Regulations). More than 50 whole ecosystem studies have been conducted at the research station, including several contaminant introductions. Beginning in 2017, a program to examine the fate and effects of crude oil spills in freshwater, including an analysis of the efficacy of minimally invasive shoreline cleanup techniques, has been conducted. This research environment provided a unique opportunity to examine the efficacy of a SWA, Corexit EC9580A $\mathrm{A}^{\mathrm{TM}}$, in a freshwater field setting.

Corexit EC9580A ${ }^{\mathrm{TM}}$ is a SWA but it can also be used as a herding agent to thicken oil slicks so that they can be ignited when in situ burning is being used as a removal method [7]. The product was developed during the Exxon Valdez oil spill response in the late 1980s and was intended for application to rocky or rip rap marine shores where it can increase recovery of stranded oil by up to $65 \%$ [8]. Removal from hard surfaces has been effective even when heavy oils have weathered for up to $4 \mathrm{~d}$ [9-11]. Field tests conducted in low energy estuarine environments have also demonstrated effectiveness of the product [12]. For example, when applied to oiled mangroves, SWA application reduced blockage of pores called lenticels in the plant's prop roots, recovering critical gas exchange [13]. Remediation of oil spills in low energy wetlands with sensitive vegetation has also been enhanced with application of SWA $[14,15]$.

To examine the efficacy of Corexit EC9580 $\mathrm{A}^{\mathrm{TM}}$ for remediating oil spills in a low energy freshwater environment, we used model spills contained in shoreline enclosures $(5 \times 10 \mathrm{~m})$ in Lake 260 at the IISD-Experimental Lakes area using a previously described approach [16]. Briefly, Cold Lake Blend diluted bitumen, obtained from industry pipeline sources, was weathered for $36 \mathrm{~h}$ in a $1.2 \mathrm{~m}$ diameter stainless steel pan over $20 \mathrm{~cm}$ of lake water. After weathering, the oil was collected from the surface of the water and $\sim 1.25 \mathrm{~kg}$ of the weathered oil was applied onto the surface of the water, $50 \mathrm{~cm}$ from the shoreline.. The oil was applied uniformly across the $5 \mathrm{~m}$ width of three replicate enclosures in each of two areas of the lake with distinct shore substrates: wetland and rock/cobble. Three additional enclosures in each shoreline environment were left unoiled as reference systems. No cleanup was initiated after oil application for $72 \mathrm{~h}$ to simulate conservative oil spill response times [17]. After $72 \mathrm{~h}$, oil on the surface of the water inside the enclosures was removed using pre-weighed polypropylene sorbent pads (Spill Ninja, MEP Brothers, Winnipeg, Canada). No attempt was made to remove oil adhered to vegetation or other shoreline substrates. The shorelines in each enclosure were then rinsed with water pumped from inside the enclosures and delivered over the oiled shoreline area through a lowpressure manifold that spanned the $5 \mathrm{~m}$ width of the enclosures and delivered streams of water at $15 \mathrm{~cm}$ intervals. Rinsing was performed for $12 \mathrm{~min}$ comprising a total rinsing volume of $1600 \mathrm{~L}$. The pumped water flowed over the oiled shoreline and back into the enclosures, where floating oil was again captured using pre-weighed sorbent pads. The next day, Corexit EC9580A ${ }^{\text {TM }}$ was applied to the oiled shorelines according to manufacturer's suggested rates $(265 \pm 8 \mathrm{~g}$ /enclosure on an approximate area of $2.5 \mathrm{~m}^{2}$. (e.g., $5 \mathrm{~m} \mathrm{X} 0.5 \mathrm{~m}$ wide strip of shoreline) using a hand-held pesticide grade garden sprayer. Thirty minutes after applying the SWA the shorelines were flushed again with water and freefloating oil was collected as described above. All sorbent pads that were used to collect oil were packaged in plastic bags and hung overnight to allow trapped water to drain. The drained and dried pads were then reweighed to determine the total mass of oil recovered from each enclosure.

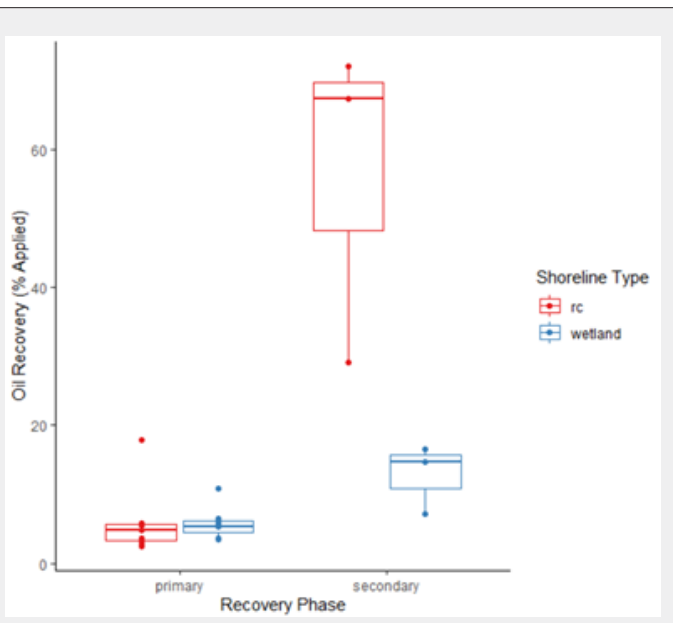

Figure 1: Percent mass of oil recovered from rock/cobble ( $\mathrm{rc}$ ) and wetland shorelines during primary recovery (freshwater flushing with absorptive media) and secondary recovery (Corexit EC9580A ${ }^{\mathrm{TM}}$ application followed by freshwater flushing with absorptive media). 
Primary remediation efforts, using only sorbent pads and freshwater rinsing, recovered approximately $6 \%$ of the original mass of weathered oil applied to both the wetland and rock/cobble shoreline environments (Figure 1). The efficacy of additional oil removal using the SWA was greater for rock/cobble shorelines ( $56 \pm 14 \%$ of the original mass of oil applied) compared to wetland shorelines with organic substrate $(13 \pm 3 \%)$. The degree of removal from rock/cobble shorelines, in our study, is similar to previous reports (26-65\%) for hard substrates [8,9]. Lower efficacy in more organic substrates is also in agreement with prior studies. For example, Corexit EC9580A ${ }^{\mathrm{TM}} \mathrm{did}$ not improve removal of stranded oil from an estuarine wetland when chemical measurements of hydrocarbons in sediment were used to assess recovery [3].

The formulation of Corexit EC9580A $\mathrm{A}^{\mathrm{TM}}$ is proprietary, but is known to contain propylene glycol, 2-butoxyethanol and a surfactant, dioctyl sodium sulfosuccinate (DOSS), which is less hydrophilic than dispersants commonly used for oil spill response $[18,19]$. In the formulation, DOSS is intended to allow oil to be released from substrates so that it coalesces on the water's surface but to limit dispersion of oil droplets into the water column [5]. In contrast, dispersants commonly used for oil spill response enhance the formation of oil droplets, increasing the surface area available for microbial degradation [2]. Surface washing agents, like Corexit EC9580A $\mathrm{A}^{\mathrm{TM}}$, are generally less toxic than dispersants but both can potentially enhance exposure and toxicity of oil in the water column and to sediment dwelling organisms [20]. The timing of post spill SWA application and freshwater flushing after application is important for optimal performance. Wave tank tests have shown that effectiveness of SWA is limited when heavy oils are weathered beyond 4d [9]. Extending the time after application and prior to flushing can also allow the SWA to lift adhered oil more effectively; however, longer soaking time also may allow partial volatilization of the SWA, stranding of the coalesced oil on the shoreline, and reduced mass recovery of oil [21]. In such cases, hydrophilic components of the SWA can also dissolve into the water, reducing chemical recovery in the system [4].

We observed that oil rinsed from our enclosure shorelines appeared more soluble and less adherent to oleophilic absorptive media than what we had observed during primary recovery, before the SWA was applied. Similar observations have also been reported after the SWA was applied to weathered diluted bitumen on granite tiles [9]. These authors also noted that removal was more limited when oil was weathered for $>4 \mathrm{~d}$. While diluted bitumen in our study was weathered for $51 / 2$ days prior to SWA application, relatively high rates of recovery were still achieved in enclosures with rock/cobble substrates. It is more likely that greater binding of oil to organic substrates in the wetland enclosures limited the ability of the SWA to remove oil, as suggested by previous studies $[2,21]$. This suggests that the SWA should be considered only for removal of oil from hard substrates.
Few studies have directly assessed the toxicity of Corexit EC9580 $\mathrm{A}^{\mathrm{TM}}$ and much of the existing literature has focused on marine applications and acute lethality endpoints [22]. The acute lethality of SWA is typically at higher concentrations (10-1000's $\mathrm{mg} / \mathrm{L}$ range) than the toxic effects of oil, which is maximally 1 $\mathrm{mg} / \mathrm{L}$ (reviewed in Chen et al. [5]). However, some concern for biological impacts at lower concentrations have been identified. Black et al. [23] reported impaired movement and buoyancy among adult water striders (Metrobates sp.) within 5 minutes of exposure to $12 \mathrm{~g}$ of the SWA applied to the water surface of $1.7 \mathrm{~m}$ diameter freshwater mesocosms. The effect was evident even when oil was not present and the authors suggested that it arose via a physical, rather than toxic, mechanism. Application of Corexit EC9580A $\mathrm{A}^{\mathrm{TM}}(1.2 \mathrm{ml}$ in $800 \mathrm{ml}$ microcosms) increased long term (186d) toxicity of both South Louisiana Crude and diesel to the freshwater sediment dwelling organism Chironomus tentans and to two test organisms that reside in the water column, Daphnia pulex and Japanese medaka (Oryzias latipes), prompting the authors to recommend against use of the product for oil spill response operations in freshwater marshes [20]. It has also been suggested that solvent-based SWAs, including Corexit EC9580 $\mathrm{A}^{\mathrm{TM}}$, may be more bioavailable to sediment bound organisms and that additional study of nearshore benthic organisms is warranted [24].

\section{Conclusion}

In conclusion, while Corexit EC9580 $\mathrm{A}^{\mathrm{TM}}$ appreciably improved oil recovery for shorelines with rock/cobble substrates in our study, recovery was only marginally improved in wetlands with organic substates. Coupled with the potential for undesirable impacts to benthic organisms and demonstrated effects on surface dwelling biota we suggest that solvent based SWAs should not be considered as part of primary oil spill response measures in low energy freshwater environments with organic sediments.

\section{References}

1. Government of Canada (2016) Regulations Establishing a List of Spilltreating Agents (Canada Oil and Gas Operations Act). Canada Gazette 150, No. 12

2. Lee K, Boufadel M, Chen B, Foght J, Hodson P, et al. (2015) The Behaviour and Environmental Impacts of Crude Oil Released into Aqueous Environments. Royal Society of Canada, Ottawa.

3. Bizzell CJ (2000) Evaluation of a shoreline cleaner for enhanced removal of petroleum from a wetland. Master's thesis, Texas A\&M University.

4. Page CA (2000) Oil spill chemical countermeasures. In near shore environments. Ph.D Thesis, Texas A\&M University. UMI\# 9980197.

5. Chen Z, An C, Boufadel M, Owens E, Chen Z, et al. (2020) Use of surface-washing agents for the treatment of oiled shorelines: Research advancements, technical applications, and future challenges. Chem Eng J 391: 123565.

6. SEA and RPI (2009, Selection Guide for Oil Spill Response Countermeasures, Volume 1 - Decision Making. Revision 5. 
7. Buist I, Potter S, Nedwed T, Mullin J (2011) Herding surfactants to contract and thicken oil spills in pack ice for in situ burning. Cold Regions Sci Tech 67(1-2): 3-23.

8. Fiocco RJ, Canevari GP, Wilkinson JB, Jahns HO, Bock J, et al. (1991) Development of Corexit 9580 - a chemical beach cleaner. Proceedings of the International Oil Spill Conference (1): 395-400.

9. Witt O’Briens (2013) Polaris Applied Sciences, Western Canada Marine Response Corporation. A study of fate and behaviour of diluted bitumen oils in marine waters; dilbit experiments, Gainford Alberta.

10. Taylor E, Challenger G, Rios J, Morris J, McCarthy MW, et al. (2014) Dilbit Crude Oil Weathering on Brackish Water: Meso-scale Tests of Behavior and Spill Countermeasures. Proc of the 35th Arctic Marine Oilspill Program (AMOP) Technical Seminar on Environmental Contamination and Response: June 3-5, 2014: Canmore (Alberta), Canada.

11. Fingas M (2015) Review of the Properties and Behaviour of Diluted Bitumens. Proceeding of the 39th Arctic and Marine Oil-spill Program Technical Seminar, Vancouver, British Columbia, Canada, pp. 470-494.

12. Stantec (2012) Summary of Clean-Up and Effects of the 2007 Spill of Oil from Trans Mountain Pipeline to Burrard Inlet, Project Report 1231-10505.

13. Teas HJ, Canevari GP, Lessard RR, Brown CD, Glenn R (1993) Saving oiled mangroves using a new non-dispersing shoreline cleaner. Proceedings of the International Oil Spill Conference 1: 147-151.

14. Pezeshki SR, DeLaune RD, Canevari GP, Lessard RR (1997) Major field test evaluates a shoreline cleaner to save oiled marsh grass. 1997 Proceedings of the International Oil Spill Conference 1: 397-402.

15. Pezeshki SR, DeLaune RD, Nyman A, Lessard RR, Canevari GP (1995) Removing oil and saving oiled marsh grass using a shoreline cleaner. Proceedings of the International Oil Spill Conference 1: 203-209.

16. Palace VP, Peters LE, Berard-Brown N, Smyth P, Shanoff T, et al. (2021)
Assessing Monitored Natural Recovery for remediating crude oil spills in freshwater environments: The Freshwater Oil Spill Remediation Study (FOReSt) at the Experimental Lakes Area, Canada. Proceedings of the International Oil Spill Conference. (In Press)

17. CEPA (Canadian Energy Pipelines Association) (2018) CEPA initiative; response time guideline.

18. Dasgupta S, Choyke S, Ferguson PL, McElroy AE (2018) Antioxidant responses and oxidative stress in sheepshead minnow larvae exposed to Corexit 9500 ® or its component surfactant, DOSS. Aquat Toxicol 194: 10-17.

19. Dave D, Ghaly AE (2011) Remediation technologies for marine oil spills: a critical review and comparative analysis. Amer J Environ Sci 7(5): 423-440.

20. Bhattacharyya S, Klerks PL, Nyman JA (2003) Toxicity to freshwater organisms from oils and oil spill chemical treatments in laboratory microcosms. Environ Pollut 122(2): 205-215.

21. Page CA, Fuller C, Autenrieth RL, Bonner JS, Louchouarn P, et al. (2001) Shoreline cleaner use in a sandy beach environment. Proceedings of the International Oil Spill Conference.

22. Stroski KM, Tomy G, Palace V (2019) The current state of knowledge for toxicity of Corexit EC9500A dispersant: A review. Crit Rev Environ Sci Technol 49(2): 81-103.

23. Black TA, Hanson ML, Palace VP, Rodriguez-Gil JL (2021) SurfaceDwelling Aquatic Insects in Low-Energy Freshwater Environments Are Highly Impacted by Oil Spills and the Surface Washing Agent Corexit EC9580A Used in Oil Spill Response. Environ Toxicol Chem 40(5): 1298-1307.

24. Hansen BH, Altin D, Bonaunet K, Beathe Øverjordet I (2014) Acute Toxicity of Eight Oil Spill Response Chemicals to Temperate, Boreal, and Arctic Species. J Toxicol EnviroN Hlth 77(9-11): 495-505.

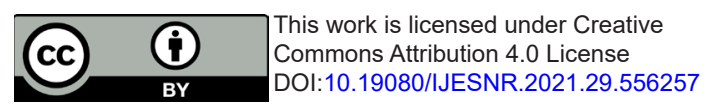

